\title{
In vitro study of nutritional and antioxidant properties of methanol extract of Nauclea latifolia root bark.
}

\author{
Ogugua Victor Nwadiogbu ${ }^{1}$, Njoku OU ${ }^{1}$, Egba Simeon Ikechukw ${ }^{2}$, Robert Ikechukw Uroko ${ }^{2 *}$, Ignatius \\ Glory ${ }^{1}$ \\ ${ }^{1}$ Department of Biochemistry, Faculty of Biological Sciences, University of Nigeria, Nsukka, Nigeria \\ ${ }^{2}$ Department of Biochemistry, College of Natural Sciences, Michael Okpara University of Agriculture, Umudike, Abia \\ State, Nigeria
}

\begin{abstract}
The study investigated some nutritional and anti-oxidant properties of methanol extract of Nauclea latifolia root bark. The nutritional and antioxidant study of the extract were carried using standard analytical procedures. Phytochemical analysis showed that the extract contains high amount of protein, saponin, total phenolics and carbohydrate with very low amount of cyanide and tannins. Vitamins $C$ and $E$ were found in high amounts while vitamin $A$ was present in moderate concentrations. The extract also possesses moderate levels of zinc, copper and manganese, however, low levels iron, nickel and selenium were detected. The extract showed no significant difference $(\mathbf{P}>\mathbf{0 . 0 5})$ when compared with the standards in the dose-dependent DPPH radical scavenging capacity, inhibition of lipid peroxidation ability, hydroxyl radical $(\mathrm{OH})$ scavenging potential. There was a significant difference $(\mathrm{P}<0.05)$ between superoxide anion $\left(\mathrm{O}_{2}^{-}\right)$scavenging capacity of the extract and ascorbic acid. The extract $(500 \mu \mathrm{g} / \mathrm{ml})$ had the highest nitric oxide radical (NO) scavenging capacity when compared to $250 \mu \mathrm{g} / \mathrm{ml}$ ascorbic acid standard. High contents of vitamins $\mathrm{C}$ and $\mathrm{E}$, phenolics compounds and moderate concentrations of trace elements like selenium might account for the good antioxidant properties exhibited by the methanol extract of Naulea latifolia root bark. The results indicate that the extract possesses high levels of antioxidant compound that could be responsible for its high antioxidant activity, thus the extract could effectively mop up free radicals and prevents its associated complications if consumed in right quantity.
\end{abstract}

Keywords: Nauclea latifolia, Free radicals, Vitamins, Antioxidants, Phytochemicals, Minerals.

Accepted on May 07, 2018

\section{Introduction}

In the past two decades, it has become increasingly clear that oxidative stress plays a major role in the pathogenesis of a number of human diseases such as atherosclerosis, chronic renal failure, ischemia/perfusion injury, neurodegenerative diseases, hypertension, cancer and diabetes mellitus [1]. There is considerable evidence that oxidative stress plays a key role in insulin resistance, impaired insulin secretion and many of the complications of diabetes such as micro/macro vascular damage [2-5]. There are several mechanisms that increase the intra and extracellular concentration of glucose resulting in oxidative stress, including the auto-oxidation of glucose, the non-enzymatic glycation of proteins and the increased production of glucose derived from advanced glycosylation end products and activation of the polyol pathway in sorbitol production [6,7]. Another mechanism that may account for hyperglycaemia-derived vascular cell dysfunction is the spontaneous formation of glucose adducts to basic amino acids (lysine and arginine) and other amine-containing molecules.
Although these early non-enzymatic glycation products are reversible (like glycohaemoglobin), they later become irreversibly modified products of glucose called "advanced glycation end-products" or AGEs, via slow and complex processes including glycation, glyco-oxidation and autooxidative glycosylation and the subsequent oxidative degradation of glycated proteins [8]. There is evidence that hyperglycaemia-induced oxidative stress occurs before the onset of diabetic complications [5]. ROS have an important role in the onset and progression of the disease, in addition to that in various physiologic and pathophysiologic complications [9].

\section{Materials and Methods}

\section{Plant minerals}

The root barks of Nauclea latifolia Sm were collected from a natural habitat in Opi, Nsukka Local Government Area of Enugu State, Nigeria and were authenticated at the Taxonomy 
Unit, Department of Plant Science and Biotechnology, Faculty of Biological Sciences, University of Nigeria, Nsukka.

\section{Chemicals and reagents}

All chemicals/reagents and drugs used for this study were of analytical grade and were obtained commercially.

\section{Preparation of Nauclea latifolia extract}

The plant material (root bark) was dried under shade in the laboratory at room temperature and then pulverized using laboratory mortar and pestle. The pulverized sample (plant crude) was then weighed using top loading electronic scale DT-100. The weighed crude plant sample was extracted with $80 \%$ methanol $(80 \mathrm{ml}$ absolute methanol $+20 \mathrm{ml}$ distilled water $)$ for $48 \mathrm{~h}$ duration by soaking after which it was filtered using Whatman filter paper. The extract was then concentrated under reduced pressure using rotary vacuum evaporator and its percentage yield determined. It was then stored in an air-tight container and preserved in the refrigerator. The percentage yield was determined as follows:

Percentage $=(($ Final $($ extract $)$ weight after concentration $) /($ Initial (crude) weight before extraction) $) \times 100$

\section{Phytochemical analysis of Nauclea latifolia smith extract}

The preliminary phytochemical screening of the methanol rootbark extract of Nauclea latifolia Smith was carried out in order to ascertain the presence of some plant secondary metabolites and thus those detected were further quantified. Both determinations were done by utilizing standard conventional protocols as illustrated by Harborne et al. [10,11].

\section{Quantitative determination of some vitamins and micronutrient contents of the extract}

This involves the determination of the various amounts of micronutrient and vitamin contained in the extract. The determinations were done by utilizing standard conventional protocols as illustrated by AOAC [12].

\section{Assay of antioxidant activities of methanol extracts of the Nauclea latifolia root bark}

Antioxidant scavenging activity of the Nauclea latifolia extract on DPPH (2, 2-diphenyl-1-picrylhydrazyl radicals (DPPH), inhibition of lipid peroxidation, hydroxyl radical scavenging $(\mathrm{OH})$ activity, superoxide radical $\left(\mathrm{O}_{2}^{-}\right)$scavenging and in vitro nitric oxide radical (NO) scavenging activity were assayed according to the methods described by Awah et al. [13].

\section{Statistical analysis}

The results obtained were statistically analyzed using one-way Analysis of Variance (ANOVA) to get the mean grouped mean (expressed as Mean \pm SD) and this was used to determine the significant difference between the grouped means at $95 \%$ confidence level (i.e. a difference in the mean values of $\mathrm{P}<0.05$ was considered statistically significant), using Statistical Package for Social Science (SPSS) version 20. Independent sample t-test and Pearson correlation analysis were also done to compare scavenging/inhibition capacities of the extract for free radicals in comparison with those of the standard antioxidants at the various determined concentrations.

\section{Results}

\section{Percentage yield of methanol in root-bark extract of Nauclea latifolia smith}

Extraction of $500 \mathrm{~g}$ finely ground crude sample of Nauclea latifolia root-bark with $1.5 \mathrm{~L} 80 \%$ methanol gave a percentage yield of $10.8 \%$.

The qualitative phytochemical constituents of the methanol root-bark extract of Nauclea latifolia in Tables 1 and 2 respectively shows that it contains relative amount of tannin, glycoside and cyanide. Saponin and reducing sugar were present at moderate amount while flavonoid, alkanoids, protein and carbohydrate were present in high quantity. Resin was not detected. All these also correlated with the obtained quantitative results (Table 2).

Table 1. Qualitative phytochemical constituents of Nauclea latifolia extract.

\begin{tabular}{lc}
\hline Phytochemical constituents & Bioavailability \\
\hline Alkaloids & ++ \\
\hline Flavonoids & ++ \\
\hline Saponins & +++ \\
\hline Tannin & + \\
\hline Protein & +++ \\
\hline Reducing sugar & ++ \\
\hline Glycoside & + \\
\hline Cardiac glycoside & + ND \\
\hline Resins & +++ \\
\hline Carbohydrate & + \\
\hline Cyanide & + \\
\hline Acidic compounds & ++ \\
\hline Key: +: Present; ++: Moderately present; +++: Highly present; ND: Not detected.
\end{tabular}

Vitamin $\mathrm{C}$ was also found to have the highest concentration followed by vitamin E, vitamin A was found in low concentration of the micronutrients were also found to be present in low to moderate amounts (Tables 3 and 4). 


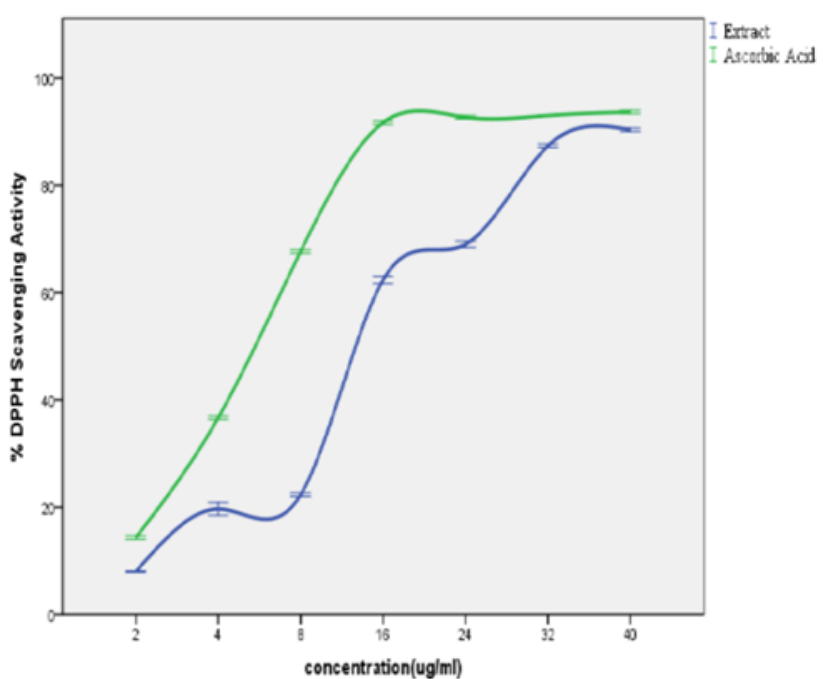

Figure 1. Free radical-scavenging activity of Nauclea latifolia Sm and ascorbic acid on 2, 2-diphenyl-1-picrylhydrazyl radicals $(\mathrm{DPPH})$.

In the Figure 1, the extract showed a significant concentrationdependent DPPH scavenging capacity with no significant difference $(p>0.05)$ from that of the ascorbic acid standard. The observed potent DPPH radical-scavenging capacity of the extract significantly $(\mathrm{p}<0.05)$ corroborated with the various concentrations of the extract and that of the standard (ascorbic acid) statistically with a good positive correlation coefficient $\left(\mathrm{R}^{2}\right)$ of 0.965 and 0.895 respectively. There exists also no significant difference $(\mathrm{p}>0.05)$ between scavenging capacities of the extract and the standard (ascorbic acid) at the various concentrations.

Table 2. Quantitative phytochemistry of Nauclea latifolia extract.

\begin{tabular}{ll}
\hline Phytochemical constituents & Concentration $(\mathbf{m g} / \mathbf{1 0 0} \mathbf{g})$ \\
\hline Alkaloids & $13.54 \pm 0.02$ \\
\hline Flavonoids & $17.33 \pm 0.03$ \\
\hline Total phenolics & $166.45 \pm 0.03$ \\
\hline Tannins & $0.05 \pm 0.01$ \\
\hline Saponins & $560 \pm 0.04$ \\
\hline Reducing sugar & $2.93 \pm 0.05$ \\
\hline Glycoside & $1.28 \pm 0.05$ \\
\hline Carbohydrate & $158.70 \pm 0.03$ \\
\hline Cyanide & $0.03 \pm 0.02$ \\
\hline Protein & $587 \pm 0.04$ \\
\hline Values are presented as mean \pm standard deviation $(\mathrm{n}=3)$.
\end{tabular}

Table 3. Quantitative determination content of vitamin A, $C$ and $E$ of Nauclea latifolia.

\begin{tabular}{ll}
\hline Vitamin A & $8.98 \pm 0.03$ \\
\hline Vitamin C & $221.08 \pm 0.02$ \\
\hline Vitamin E & $198.80 \pm 0.03$ \\
\hline Values are presented as mean \pm standard deviation $(n=3)$.
\end{tabular}

Table 4. Quantitative determination of micronutrients content of Nauclea latifolia.

\begin{tabular}{ll}
\hline Micronutrient $(\mathbf{m g} / \mathbf{1 0 0 g})$ & Concentration $\mathbf{( m g / 1 0 0 ~ g ) ~}$ \\
\hline Selenium & $0.28 \pm 0.01$ \\
\hline Copper & $2.23 \pm 0.02$ \\
\hline Zinc & $5.42 \pm 0.02$ \\
\hline Nickel & $0.66 \pm 0.06$ \\
\hline Iron & $0.90 \pm 0.04$ \\
\hline Manganese & $1.71 \pm 0.02$ \\
\hline
\end{tabular}

Values are presented as mean \pm standard deviation $(n=3)$.

In Figure 2, the extract showed a significant concentrationdependent inhibition capacity of lipid peroxidation with no significant difference $(p>0.05)$ from that of the butylated hydroxytoluene standard. Inhibition of lipid peroxidation capacity of the extract showed a statistically significant correlation $(p<0.05)$ with the concentration of the extract and that of the standard (butylated hydroxytoluene) with a strong positive correlation coefficient $\left(\mathrm{R}^{2}\right)$ of 0.884 and 0.977 respectively. There was also no significant difference $(\mathrm{p}>0.05)$ between the inhibition capacities of the extract and that of the standard (butylated hydroxytoluene) at the various concentrations. The extract showed IC50 value comparable with butylated hydroxytoluene (IC50=24.3 $\pm 1.92 \mu \mathrm{g} / \mathrm{ml})$.

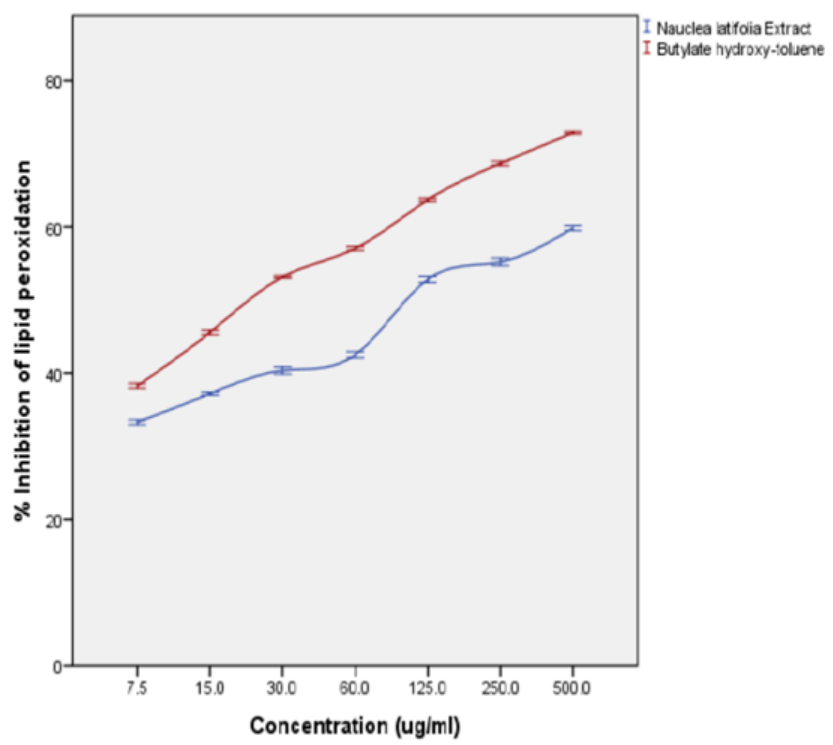

Figure 2. Inhibition of lipid peroxidation activity of $N$. latifolia and butylated hydroxytuolene. 
From the figure above, the extract was able to scavenge hydroxyl radical $(\mathrm{OH}$.) radical in a concentration-dependent mode with no significant difference $(\mathrm{p}>0.05)$ from those of the $\alpha$-tocopherol standard. There is also no significant difference ( $p>0.05$ ) between the $\mathrm{OH}$ scavenging capacities of the extract and those of the standard ( $\alpha$-tocopherol) at the various concentrations. The hydroxyl radical $(\mathrm{OH}$.) scavenging activity of the extract was statistically significant $(p<0.05)$ when correlated with the concentrations of the extract and standard ( $\alpha$-tocopherol) with a good positive correlation coefficient $\left(\mathrm{R}^{2}\right)$ of 0.834 and 0.993 respectively. The extract was found to be powerful quencher of $\mathrm{OH}(\mathrm{IC} 50=37.6 \pm 4.7 \mu \mathrm{g} / \mathrm{ml})$ compared to $\alpha$-tocopherol $(\mathrm{IC} 50=38.9 \pm 2.8 \mu \mathrm{g} / \mathrm{ml})$ (Figure 3 ).

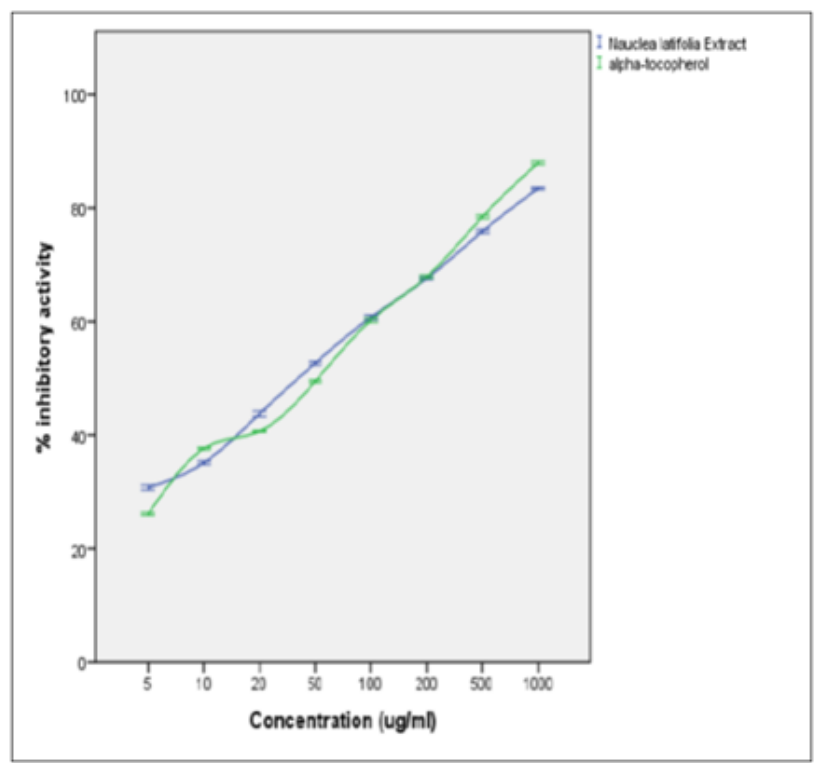

Figure 3. Inhibition of hydroxyl radical by Nauclea latifolia and alpha-tocopherol (standard).

Figure 4 above shows that the extract was able to inhibit the formation of reduced Nitroblue Tetrazolium (NBT) in a concentration-related manner. However, the extract was found to have a lower $\mathrm{O}_{2}^{-}$(superoxide anion) scavenging activity $(\mathrm{IC} 50=82.5 \pm 2.63)$ when compared to the standard rutin $(\mathrm{IC} 50=3.3 \pm 0.2)$. The superoxide anion $\left(\mathrm{O}_{2}^{-}\right.$.) scavenging activity of the extract significantly $(\mathrm{p}<0.05)$ correlated with the concentrations of the extracts and standard (rutin) with a good positive correlation coefficient $\left(\mathrm{R}^{2}\right)$ of 0.898 and 0.859 respectively. However, there exist a significant difference $(p<0.05)$ between the scavenging capacities of extract and those of the rutin (standard) at the various concentrations.

From Figure 5, the nitric oxide (NO) scavenging capacity was concentration dependent with $500 \mu \mathrm{g} / \mathrm{ml}$ scavenging most effectively; at the $30^{\text {th }}$ and $60^{\text {th }}$ min there was no significant $(p>0.05)$ reduction in nitrite ions showing little scavenging activity of nitric oxide by both the extract and ascorbic acid standard. But at the $90^{\text {th }} \mathrm{min}, 250,500 \mu \mathrm{g} / \mathrm{ml}$ of the extract and $500 \mu \mathrm{g} / \mathrm{ml}$ of ascorbic acid scavenged nitric oxide which is shown as a reduction in the concentration of nitrite ions. At the $120^{\text {th }} \mathrm{min}$, only $500 \mu \mathrm{g} / \mathrm{ml}$ scavenged at a significant level; at the $150^{\text {th }} \mathrm{min}$, only $500 \mu \mathrm{g} / \mathrm{ml}$ significantly scavenged the nitric oxide radical; at the $180^{\text {th }} \mathrm{min}$, both $500 \mu \mathrm{g} / \mathrm{ml}$ and 250 $\mu \mathrm{g} / \mathrm{ml}$ of the extract scavenged the nitric oxide radical to a very significant $(\mathrm{p}<0.05)$ level. The overall reducing ability shows that the extract at $500 \mu \mathrm{g} / \mathrm{ml}$ was most potent followed by the extract at $250 \mu \mathrm{g} / \mathrm{ml}$ and then ascorbic acid at $500 \mu \mathrm{g} / \mathrm{ml}$ (MENL=Methanol extract of Nauclea latifolia).

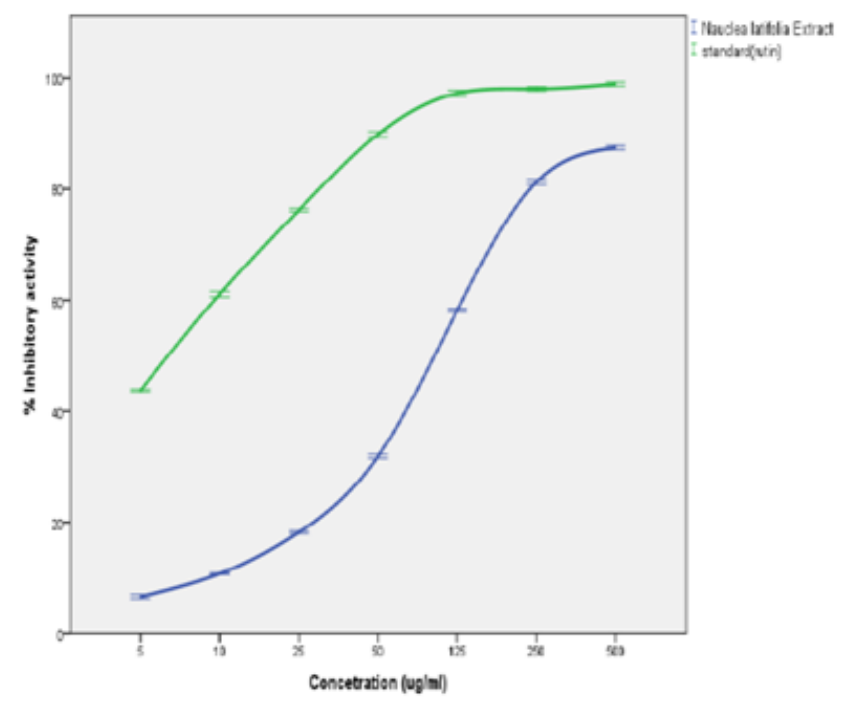

Figure 4. Inhibition of superoxide anion by Nauclea latifolia Sm and Rutin (standard).

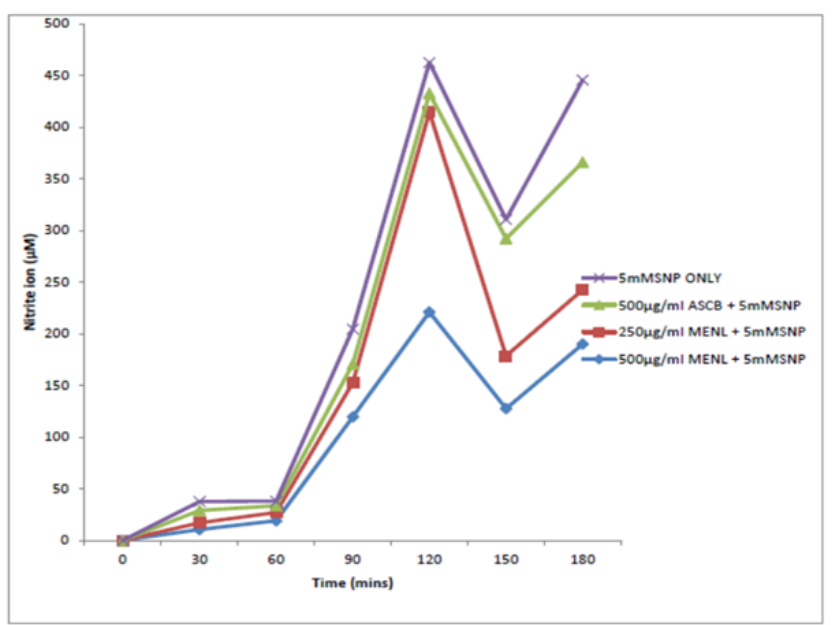

Figure 5. In vitro nitric oxide radical scavenging activity of Nauclea latifolia Sm and ascorbic acid (standard).

\section{Discussion}

The study investigated some nutritional and antioxidant properties of methanol extract of Nauclea latifolia root bark to validate existing claims and for possible maximization of these properties for human benefits. The percentage yield of $10.8 \%$ makes methanol root-bark extracts of Nauclea latifolia Smith a good source of antioxidants and some other important plant secondary metabolites. The high percentage yield, with preserved integrities of the extracts is an indication of the fact that this method can be adapted as a standard method of extract preparation. This is in contrast to the percentage yield of 
ethanol stem-bark extract of $7.63 \mathrm{~g}$ reported by Ogbuehi et al. [14]. This disparity in the results could be due to the phytochemical constituents of the different plants parts and difference in the extraction solvents and/or methods.

The phytochemical (qualitative and quantitative) analysis revealed the presence of active principles such as tannins, cardiac glycosides and cyanide in trace amount, reducing sugars and glycosides in moderate concentration and flavonoid, total phenolics, saponin, alkaloid, protein and carbohydrates in high amounts. This is consistent with the result of Anowi et al. except for tannins and resins that were not detected in their results [15]. The high content of saponins and tannins could be the basis for its antimicrobial activity as reported by Nworgu et al. [16]. Phenolic compounds have also been reported to possess antimicrobial properties [17]. Alkaloids, tannins, saponins, glycosides and steroid derived from plants have been shown to have antimicrobial effect and pharmacological activities [11]. The inhibitory activity exhibited by these secondary metabolites tends to agree with the reports of Adeyemi et al., both of which linked the antimicrobial and antioxidant properties of plants to the presence of secondary metabolites $[18,19]$. Flavonoids are most commonly known for their antioxidant activity similar to those of vitamins $\mathrm{C}$ and $\mathrm{E}$ [20]. Saponin has been reported to reduce the uptake of certain nutrients including glucose and cholesterol at the gut through intraluminal physicochemical reaction [21].

The vitamin compositions showed vitamin A $(8.98 \pm 0.03$ $\mathrm{mg} / 100 \mathrm{~g})$, vitamin E $(198.80 \pm 0.02 \mathrm{mg} / 100 \mathrm{~g})$ and vitamin C $(221.08 \pm 0.02 \mathrm{mg} / 100 \mathrm{~g})$ in a low, relatively high and very high amounts and it indicates that the extract could be able to inhibit lipid peroxidation in both aqueous (e.g. vitamin C) and lipid phase (e.g. vitamin A and E) of the cell [22]. This finding corroborate with earlier reports by Evans et al., on the use of the plant as a strong anti-oxidant agent and also in agreement with anti-oxidant properties of other medicinal plant [2,23]. The Nauclea latifolia root-bark extract exhibited strong antioxidant potentials which may be attributed to the various constituent phytochemicals as revealed in their appreciable amounts in this work. Therefore, Nauclea latifolia could be exploited in the development of neutraceuticals.

Antioxidant enzymes such as glutathione peroxidase (GSH$\mathrm{Px}$ ), catalase (CAT), and superoxide dismutase (SOD) that metabolize toxic, oxidative intermediates require micronutrient cofactors such as $\mathrm{Se}, \mathrm{Fe}, \mathrm{Cu}, \mathrm{Zn}$ and $\mathrm{Mn}$ for optimum catalytic activity [22]. It is only when these metals/micronutrients are delivered in the diet in sufficient amounts those animals can synthesize these antioxidant enzymes [24]. The ability of copper and iron to easily accept and donate electrons explains their important roles in oxidation-reduction reactions and in scavenging free radicals [17]. In contrast, deficiency of these elements could cause oxidative stress and damage to biological molecules and compromise the integrity of the lipid bi-layer membranes [25]. Excessive amount of these trace minerals/ metals such as $\mathrm{Fe}$ and $\mathrm{Cu}$ could propagate the formation of more reactive free radicals by fenton reaction that is capable of forming very potent hydroxyl radicals implicated in lipid peroxidation of polyunsaturated fatty acids [22]. From the result obtained in this study, these trace elements were present in minute to moderate amount.

The Nauclea latifolia extract showed a significant $(\mathrm{P}<0.05)$ concentration-dependent DPPH radical scavenging capacity. The antioxidants in the crude extract were able to neutralize the free radical character of DPPH probably by transferring either electron or hydrogen atoms to DPPH, thereby changing the colour from purple to the yellow-coloured diphenylpicrylhydrazine [26]. This interaction depends on the structural conformation of the bioactive compounds present in the plant extract among which the hydroxyl groups of flavonoids are highly favourable [27]. The observed potent DPPH radical-scavenging capacity of the extract significantly $(p<0.05)$ corroborated with the concentration of the extract and standard (ascorbic acid) with a good positive correlation coefficient $\left(\mathrm{R}^{2}\right)$ of 0.965 and 0.895 respectively. There exists also no significant difference $(\mathrm{p}>0.05)$ between DPPH scavenging capacities of the extract and the standard (ascorbic acid) at the various determined concentrations. This result is in line with the use of plants as radical scavenger and also is in agreement with anti-oxidant properties of other medicinal plants [13,27]. Rana et al. reported antioxidant activity of alcoholic extract of medicago sativa L. as estimated by IC50 of $100.38 \mu \mathrm{g} / \mathrm{ml}$ (DPPH radical scavenging capacity); and thus related this to the anti-diabetic, anti-oxidant and free radical scavenging potentials of the extract.

Lipid peroxidation involves the formation and propagation of lipid radicals with numerous deleterious effects including destruction of metabolic lipids, metabolic disorders, inflammation and production of malondialdehyde (MDA) being the hallmark of this process [28,29]. Inhibition of lipid peroxidation was assessed by the amount of MDA produced. The plant extract did not induce any basal lipid peroxidation in the yolk homogenate. The extract showed a significant $(p<0.05)$ concentration-dependent inhibition. This corroborates with the observed high $\mathrm{OH}$ radical scavenging activity of the extracts and suggests that the extract may afford a cytoprotective effect [23]. Inhibition of lipid peroxidation capacity of the extract significantly $(p<0.05)$ correlated with the concentration of the extract and that of the standard (butylated hydroxytoluene) with a strong positive correlation coefficient $\left(\mathrm{R}^{2}\right)$ of 0.884 and 0.977 respectively. This result is in agreement with the report of some researched antioxidant medicinal plants $[30,31]$.

Hydroxyl radical (OH.) generated by $\mathrm{Fe}^{3+}$ ion was measured by determining the degree of deoxyribose degradation. The extract was found to significantly $(\mathrm{p}<0.05)$ scavenge $\mathrm{OH}$ in a concentration-dependent manner. The scavenging ability of the extract was not significantly different $(p>0.05)$ from that of the standard ( $\alpha$-tocopherol) at all tested concentrations. The extract was also found to be powerful quencher of $\mathrm{OH}$ thereby preventing the propagation of lipid peroxidation (IC50 $=37.6 \pm$ $4.7 \mu \mathrm{g} / \mathrm{ml}$ ) in comparison to $\alpha$-tocopherol (IC50=38.9 $\pm 2.8 \mu \mathrm{g} /$ $\mathrm{ml})$. The antioxidants in the plant extract competed against the $\mathrm{OH}$ generated from the $\mathrm{Fe}^{3+}$ dependent system for deoxyribose. 
The antioxidants in this plant extract could be acting as chelators of the $\mathrm{Fe}^{3+}$ ions in the system, thereby preventing them from forming complex with the deoxyribose or simply by donating hydrogen atoms and accelerating the conversion of $\mathrm{H}_{2} \mathrm{O}_{2}$ to $\mathrm{H}_{2} \mathrm{O}$ [32]. The observed ability of the extract to scavenge or inhibit the $\mathrm{OH}$ indicates that the extract could significantly $(\mathrm{p}>0.05)$ inhibit lipid peroxidation in comparison with the standard ( $\alpha$-tocopherol) since $\mathrm{OH}$ is highly implicated in peroxidation. The hydroxyl radical $(\mathrm{OH})$ scavenging activity of the extract significantly $(p<0.05)$ correlated with the concentration of the extract and those of the standard $(\alpha-$ tocopherol) with a good positive correlation coefficient $\left(\mathrm{R}^{2}\right)$ of 0.834 and 0.993 respectively. There was also no significant $(p>0.05)$ difference between the hydroxyl radical $(\mathrm{OH})$ scavenging capacity of the extract and that of the standard $(\alpha-$ tocopherol) at the various concentrations determined which is in agreement with the report of Nwanna et al. [33].

Flavonoids are potent scavengers of the superoxide radicals. The Nauclea latifolia extract significantly $(\mathrm{p}<0.05)$ inhibited the formation of reduced NBT in a concentration-related manner. However, the extract was found to have a lower superoxide anion $\left(\mathrm{O}_{2}^{-}\right.$.) scavenging activity ( $\mathrm{IC} 50=82.5 \pm 2.63$ $\mu \mathrm{g} / \mathrm{ml}$ ) when compared to the standard rutin (IC50=3.3 \pm 0.2 $\mu \mathrm{g} / \mathrm{ml})$. The $\mathrm{O}_{2}^{-}$scavenging effect of the extract could culminate in the prevention of $\mathrm{OH}$ radical formation since $\mathrm{O}_{2}{ }^{-}$ and $\mathrm{H}_{2} \mathrm{O}_{2}$ are required for $\mathrm{OH}$ radical generation via the fenton reactions. The scavenging potential would depend on the number and locations of the hydroxyl groups in the phenolic compounds present in the extracts [34]. The superoxide anion $\left(\mathrm{O}_{2}^{-}\right)$scavenging activity of the extract significantly $(\mathrm{p}<0.05)$ correlated with the concentrations of the extract and that of the standard (rutin) with a correlation coefficient $\left(\mathrm{R}^{2}\right)$ of 0.898 and 0.859 respectively. There was no significant $(\mathrm{p}>0.05)$ difference between the scavenging potential of the extract and the rutin (standard) at the various determined concentrations. This is in agreement with the report that generation of superoxide radicals are inhibited by tannins [35]. Singha et al. report a dose dependent superoxide radical scavenging activity of Ichnocarpus frutescens (Linn) compared with butylated hydroxyanisole [36]. It showed $51.484 \%$ of inhibition at the 75 $\mu \mathrm{g} / \mathrm{ml}$ of extract concentration, whereas, the positive control (L-ascorbic acid) had $73.969 \%$ of inhibition at the same concentration in line with the report of Rana et al. [28].

Despite the possible beneficial effects of nitric oxide radicals (NO), its contribution to oxidative damage is increasingly becoming evident [37]. This is due to the fact that NO can react with superoxide to form the peroxynitrite anion which is a potential strong oxidant that can decompose to produce $\mathrm{OH}$ and $\mathrm{NO}_{2}$ [37,38]. Nitric oxide radicals (NO) released from Sodium Nitroprusside (SNP) has a strong NO character which can alter the structure and function of many cellular components. The result of the study showed that the extract in SNP solution decreased the level of nitrite, a stable oxidation product of NO liberated from SNP. The extract exhibited strong NO radical scavenging activity leading to the reduction of the nitrite concentration in the assay medium, a possible protective effect against oxidative damage. The NO scavenging capacity of the Nauclea latifolia extract was concentration dependent with $500 \mu \mathrm{g} / \mathrm{ml}$, scavenging most effectively in comparison with the ascorbic acid standard; the fluctuating scavenging activity observed at $30 \mathrm{~min}$ intervals might be as a result of complex formation which tends to dissociate or proceed to form nitrite ion. This is healthy in a system where nitric oxide serves as a two-edged sword, it could be beneficial or deleterious [39]. This equilibrium point can be drawn to favour high nitric oxide radical (NO) production thereby promoting its role in immune system integrity or to nitrite $\left(\mathrm{NO}_{2}^{-}\right)$which indicates reduced production of nitric ions [37]. Thus, there is need for a moderate scavenging activity for nitric oxide to carry out its role in immunity. This also clearly indicates that root bark extract of Nauclea latifolia could be an important source of natural antioxidants and it is agreement with the report of Senguttuvan et al. [40,41].

From all evidences obtained from this study suggest that, the plant extract has considerable antioxidant and anti-scavenging potentials. Thus, could be used in the management of oxidative stress-mediated diseases and disease states like diabetes mellitus.

\section{Conflict of Interest Statement}

Authors declare no conflict of interest.

\section{References}

1. Mates JM, Perez-Gomez C, NunezDeCastro I. Antioxidant enzymes and human diseases. Clin Biochem 1999; 32: 595-603.

2. Evans JL, Goldfine ID, Maddux BA. Oxidative stress and stress activated signaling pathways: A unifying hypothesis of type 2 diabetes. Endocrine Rev 2002; 23: 599-622.

3. Ceriello A, Motz E. Is oxidative stress the pathogenic mechanism underlying insulin resistance, diabetes, and cardiovascular disease? The common soil hypothesis revisited. Arterioscler Thromb Vasc Biol 2004; 24: 816-824.

4. Ahmed R. The physiological and biochemical effects of diabetes on the balance between oxidative stress and antioxidant defense system. Med J Islamic World Acad Sci 2005; 15: 31-42.

5. Rahimi R, Nikfar S, Larijani B. Assessment of some medical plants for hypoglycaemic activities in rats and rabbits. Biosci Biotechnol Res Community 2005; 12: 1-2.

6. Brownlee M. The pathobiology of diabetic complications. Diabetes 2005; 54: 1615-1620.

7. Soliman GZA. Antimicrobial and hypoglycemic effects of Momordica balsamina Linn. J Natural Products 2008; 1: 03-09.

8. Vlassara H. Recent progress on the biology and clinical significance of advanced glycosylation end products. J Laboratory Clin Med 1994; 124: 19-30.

9. D'Souza A, Hussain M, Howarth FC. Pathogenesis and pathophysiology of accelerated atherosclerosis in the diabetic heart. Mol Cell Biochem 2009: 331: 89-116. 
10. Harborne JB. Phytochemical methods: A guide to modern techniques of plant analysis (3rd ed). Chapman and Hall, London 1998; 88-185.

11. Trease GE, Evans MC. Textbook on pharmacognosy (13th ed). Bailiere Tandall 1989; 200-775.

12. AOAC. In: official methods of analysis (13th edition). Association of Analytical Chemists, Washington DC, USA 1970.

13. Awah FM, Uzoegwu PN, Oyugi JO. Free radical scavenging activity of and immunomodulatory effect of Stachytarpheta angustifolia leaf extract. Food Chemistry 2010; 119: 1409-1416.

14. Ogbuehi RA, Mandarino LJ, Gerich JE. Dose-response characteristics for effects of insulin on production and utilization of glucose in man. Am J Physiol 2014; 240: 630-639.

15. Anowi CF, Cardinal NC, Ezugwu CO. Antimicrobial properties of the chloroform extract of the stem bark of Nauclea latifolia. Int J Pharm Pharmacol Sci 2012; 4: 744-750.

16. Nworgu AE, Manickam AS, Nwafor A. Preliminary studies of blood pressure lowering effect of Nauclea latifolia in rats. Afr J Pharm Pharmacol 2008; 2: 37-41.

17. Olugbemiro NM, Adewumi AM, Toyin YM. Phytochemical and mineral constituents of Cochlospermum planchonii root. Biores Bulletin 2011; 5: 51-56.

18. Adeyemi KO, Oladapo O, Okwara CE. Screening of crude extracts of six medicinal plants used in South-West Nigerian unorthodox medicine anti-methicillin resistant Straphylococcus aureus activity. Alternative Med 2005; 5: 1-7.

19. Junaid SA, Olabode AO, Onwuliri FC. The antimicrobial properties of Ocimum gratissimum extracts on some selected bacteria gastro-intestinal isolates. Afr J Biotechnol 2006; 5: 2315-2321.

20. Egbung GE, Atangwho IJ, Iwara IA. The anti-diabetic efficacy of combined extracts from two continental plants: Azadirachta indica and Vernonia amygdalina. J Med Sci 2011; 2: 1185-1188.

21. Geetha BS, Mathew BC, Augusti KT. Hypoglycemic effects of leucodelphinidin derivative isolated from Ficus bengalensis Linn. Indian J Physiol Pharmacol 1994; 38: 220-222.

22. Weiss WP. Medicinal plants of India with anti-diabetic potential. J Ethnophamacol 2005; 81: 81-100.

23. Lagnika L, Anago E, Sanni A. An overview of Indian novel traditional medicinal plants with antidiabetic potentials. J Med Plant Res 2011; 5: 773-777.

24. Ryan-Harshman M, Aldoori W. The relevance of selenium to immunity, cancer, and infectious/ inflammatory diseases. Canadian J Dietetic Pract Res 2005; 66: 98-102.

25. Fremont L. Biological effects of resveratrol. Life Sci 2000; 66: 663-673.

26. Naik E, Mestrez F, Sturis J. Estimation of insulin secretion rates from C-peptide levels. Comparison of individual and standard kinetic parameters for C-peptide clearance. Diabetes 2003; 41: 368-377.

27. El-Sayed R. Pathogenesis of type 2 diabetes: Tracing the reverse route from cure to cause. Diabetologia 2009; 51: 1781-1789.

28. Khalaf NA, Shakya AK, Al-othman A. Antioxidant activity of some common plants. Turkish J Biol 2008; 32: 51-55.

29. Rana MG, Katbamna RV, Padhya AA. In vitro antioxidant and free radical scavenging studies of alcoholic extract of Medicago sativa L. Romanian J Plant Biol 2010; 55: 15-22.

30. Mano T, Shinohara R, Sawai Y. Changes in lipid peroxidation and free radical scavengers in the brain of hyperthyroid and hypothyroid aged rats. J Endocrinol 1995; 147: 361-365.

31. Yamagishi S, Matsui T. Nitric oxide, a Janus-faced therapeutic target for diabetic microangiopathy-friend or foe? Pharmacol Res 2011; 64: 187-194.

32. Kahkonen MP, Hopia AI, Vuorela HJ. Antioxidant activity of plant extracts containing phenolic compounds. J Agriculture Food Chem 1999; 47: 3954-3962.

33. Wang ME, Bunck MC, Pouwels PJ. Pancreatic fat content and beta-cell function in men with and without type 2 diabetes. Diabetes Care 2007; 30: 2916-2921.

34. Nwanna Y, Hirose H, Ohneda M. Hypoglyceamic and antihyglycemic effects of diethyl ether fraction isolated from the aqueous extract of the leaves of Cogniauxia podoleana Baillon in normal and alloxan-induced diabetic rats. J Ethnopharmacol 1994; 92: 229-232.

35. Halliwell R. An overview of Malian novel traditional medicinal plants with antidiabetic potentials. Afr J Trad Complementary Altern Med 1994; 7: 10-19.

36. Chung KT, Wong TY, Wei CI. Tannins and human health: A review. Rev Food Sci Nutr 1998; 38: 421-464.

37. Singha AK, Bhattacharjee B, Das N. Ichnocarpus Frutescens (Linn): A plant with different biological activities. Asian J Pharm Clin Res 2013; 6: 74-77.

38. Pacher HD, Amico E, Farilla L. Fatty acid translocase is localized on insulin-containing granules in human pancreatic beta-cells and mediates fatty acid effects on insulin secretion. Diabetes 2007; 54: 472-481.

39. Beckman A, Koppenol B. Free fatty acid mediated impairment of glucose-stimulated insulin secretion in nondiabetic Oji-Cree individuals from the Sandy Lake community of Ontario, Canada: A population at very high risk for developing type 2 diabetes. Diabetes 1996; 52: 1485-1495.

40. Rajesh PM, Natvar PJ. In vitro antioxidant activity of coumarin compounds by DPPH, Superoxide and Nitric oxide free radical scavenging methods. J Advanced Pharm Edu Res 2011; 1: 52-68.

41. Senguttuvan J, Paulsamy S, Karthika K. Phytochemical analysis and evaluation of leaf and root parts of the medicinal herb, Hypochaeris radicata $L$. for in vitro 
antioxidant activities. Asian Pacific J Tropical Biomed 2014; 4: 359-367.

\section{*Correspondence to}

Robert Ikechukw Uroko

Department of Biochemistry
College of Natural Sciences

Michael Okpara University of Agriculture

Umudike

Abia State

Nigeria 